\title{
Nicorandil Induced Perianal Ulceration
}

\author{
Tiernan JP, ' Baraza W, ' Chelham W, ' garner J, ${ }^{1}$ Angel C, ${ }^{1}$ Shrestha BM ${ }^{1}$ \\ 'Department of General Surgery, Sheffield Teaching Hospitals NHS Trust, United Kingdom.
}

\begin{abstract}
Nicorandil is a cardioprotective drug which is used in the prophylaxis and long-term treatment of angina pectoris. Debilitating perianal ulcer is a rare complication of Nicorandil therapy which can cause diagnostic and management dilemmas. We describe the management of a case of Nicorandilinduced perianal ulcer and review pertinent contemporary literature.
\end{abstract}

Key Words: cardioprotection, ischaemia, Nicorandil, perianal ulcer

\section{INTRODUCTION}

The potassium channel activating drug Nicorandil (2nicotinamidethyl nitrate) is used in the prophylaxis and long-term treatment of angina pectoris because of its proven efficacy and cost-effectiveness. ${ }^{1}$ Nicorandil therapy has been linked to perianal ulceration, which can be debilitating and can pose diagnostic dilemmas. ${ }^{2} \mathrm{We}$ report our experience of managing a case of Nicorandilinduced perianal ulcer and present an up-to-date review of literature related to this condition.

\section{CASE REPORT}

An 86-year-old male presented with a five-week history of perineal pain following a fall onto a toilet which was associated with minimal trauma. He complained of persistent perineal pain with associated constipation and fever. He had a past medical history of two myocardial infarctions and had been taking nicorandil at a dosage of $20 \mathrm{mg}$ twice daily for over three years. On examination, the patient was comfortable and there were no signs of sepsis. There was a very tender, deep, ulcerated area extending from the base of the scrotum posteriorly to the anal verge. Due to patient discomfort, an examination under anaesthesia was performed and biopsies taken. The ulcer was seen to extend to, but not involve, the sphincter complex (Figure 1).

His nicorandil was immediately stopped and other cardiac medications adjusted to provide maximal cardioprotection. Subsequent histopathological analysis confirmed non-specific ulceration with no evidence of dysplasia, granulomata or neoplasia, consistent with nicorandil-induced ulceration (Figure 2). Following nine days of simple wound management on the surgical ward in the form of daily dressing changes, he was discharged. In the community, a district nurse visited him weekly to continue wound care. By four months the ulcer had completely healed and there was no evidence of recurrence at six month follow-up.

\section{DISCUSSION}

Nicorandil, an adenosine triphosphate-sensitive potassium channel opener, was introduced for the first time in Japan in 1984 for the management of ischaemic heart disease. Potassium channel activation, causes arterial dilatation leading to reduced cardiac afterload, while the adjunctive nitrate effect of nicorandil decreases preload. ${ }^{3}$ It is absorbed in the small intestine and undergoes hepatic metabolism, reaching the

\author{
Correspondence: \\ Dr. JP Tiernan \\ Department of General Surgery \\ Sheffield Teaching Hospitals NHS Trust \\ Sheffield, S5 7AU, United Kingdom. \\ Email: jitiernan@doctors.org.uk
}




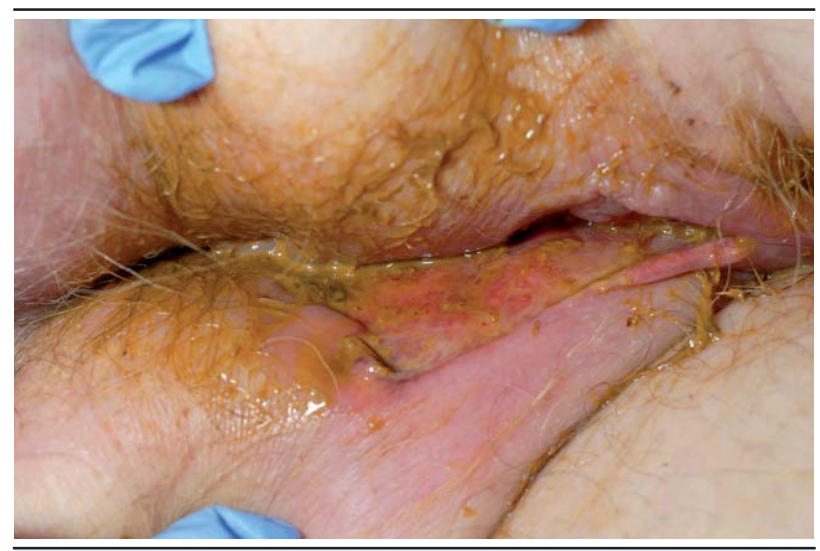

Figure 1. Perianal ulcer as seen in the left-lateral position

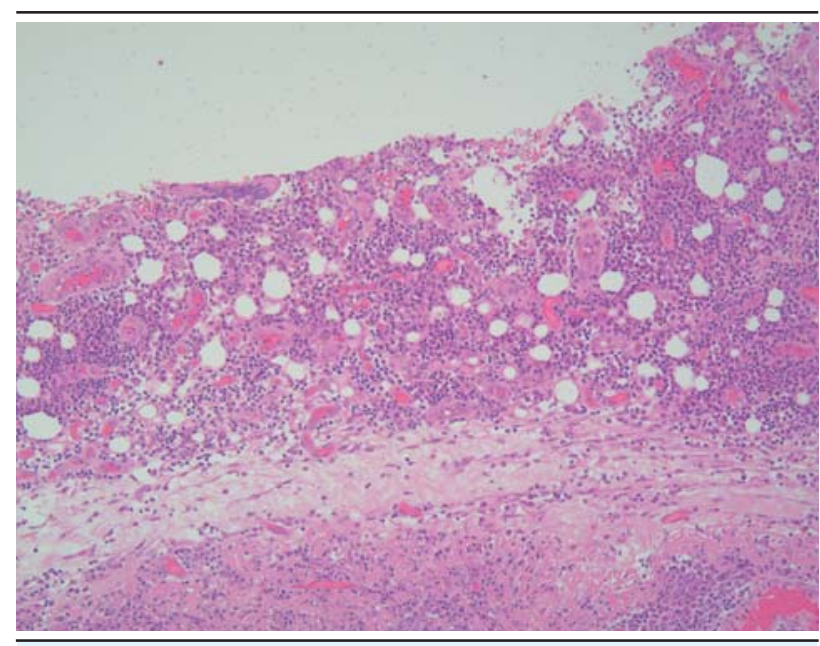

Figure 2. Histology showing chronic inflammation in the connective tissue

systemic circulation bound weakly to plasma proteins. It is metabolised by denitration into the nicotinamide pathway. ${ }^{4}$

A land-mark study, the Impact Of Nicorandil in Angina, the IONA-trial in 2001, which randomised 5126 patients with stable angina to placebo or nicorandil $20 \mathrm{mg}$ twice daily, showed a significant reduction in the death as a result of coronary heart disease, nonfatal myocardial infarction, and admissions for cardiac chest pain who received nicorandil compared to those on the placebo group. ${ }^{5}$ This led to wider acceptance of nicorandil worldwide.

Nicorandil is generally well tolerated, but a number of side-effects, including headache, nausea and dizziness are reported. More specific side-effects such as oral ulceration and stomatitis was first reported in 1998, ${ }^{6}$ which was subsequently followed by reports of anal ulceration. ${ }^{7,8}$ More recently, it has emerged that nicorandil can also cause very painful chronic ulceration of the colon and small intestine. ${ }^{9,10}$ Painful parastomal ulceration has also been reported in patients with ileostomies or colectomies. ${ }^{11}$ Gastrointestinal ulceration has been reported from the mouth to the perineum. It is sometimes associated with skin, peri-vulvar and penile ulcers. ${ }^{12-14}$

Patients typically present with severe anal pain, bleeding, discharge, and ulceration, refractory to surgical management. This may follow minor injuries including following minor anorectal procedures such as biopsy. ${ }^{15}$ Macroscopically, the ulcers vary in size but are well circumscribed, with undermined edges. Histological examination usually reveals non-specific inflammatory changes, which is an essential investigation to exclude other causes of anal ulceration including inflammatory bowel diseases, tuberculosis, sarcoidosis, sexually transmitted diseases and malignancies. ${ }^{16}$

The pathophysiology of the ulceration remains unclear. Several hypotheses have been postulated. However, there is no strong evidence to support any of these theories. Suggested mechanisms like vascular steal phenomenon induced by the vasodilator effect with associated ischaemia has been suggested yet both the oropharynx and perineum are well vascularised areas, not usually associated with vascular compromise. ${ }^{17}$ An alternative theory relates to a direct toxic effect; this is more likely to be a systemic effect in the case of anal ulceration as nicorandil has minimal faecal excretion. By contrast, oral ulceration may be due to a more local toxic effect and therefore dose-related. ${ }^{18}$ Others have suggested hypersensitivity reaction to the drug causing the ulceration. ${ }^{19}$

Prior to the recognition of the association of anal ulceration and nicorandil therapy, anal ulcers were very debilitating and refractory to treatment and were treated with diversion of faecal stream with colostomy and immunosuppressive agents. ${ }^{20}$ However, lately, vast majority of cases have shown healing following withdrawal of nicorandil. The median time for the ulcers to heal is reported as 12 weeks. ${ }^{21}$

Failure to recognise nicorandil as the cause of this condition may result in unnecessary surgery, ranging from debridement to salvage abdominoperoneal resection. Results following surgical management where nicorandil was continued were poor. ${ }^{22}$

Whilst there has been a decline in mortality due to ischaemic heart disease in developed countries, the disease is increasing in the developing world. ${ }^{23}$ It is predicted that an "epidemiological transition," in which control of infectious, parasitic and nutritional diseases will lead to populations reaching ages in which cardiovascular disease (CVD) manifests itself, will result in a CVD epidemic by the year $2020 .{ }^{24,25}$ It is therefore 
feasible that the use of nicorandil in the prophylaxis and treatment of angina will become more common in such areas; both physicians and surgeons should be aware of perianal ulceration as a potential side-effect and be prepared to omit nicorandil and maximise other cardioprotective medications.
This group of patients with severe cardiovascular disease require multidisciplinary team approach with group of specialists comprising of surgical, geriatric, medical and cardiologists so that safe substitution of nicorandil and appropriate management of the perianal ulcer is instituted.

\section{REFERENCES}

1. Walker A, McMurray J, Stewart S, Berger W, McMohan AD, Dargie H, et al. Economic evaluation of the impact of nicorandil in angina (IONA) trial. Heart. 2006;92(5):619-24.

2. Watson A, Al-Ozairi O, Fraser A, Loudon M, O'Kelly T. Nicorandil associated anal ulceration. Lancet. 2002 Aug 17;360(9332):546-7.

3. Yanagisawa T, Satoh K, Taira N. Circumstantial evidence for increased potassium conductance of membrane of cardiac muscle by 2-nicotinamidoethyl nitrate (SG-75). Jpn J Pharmacol. 1979 Oct; 29(5):687-94

4. Frydman A. Pharmacokinetic profile of nicorandil in humans: an overview. J Cardiovasc Pharmacol. 1992;20 Suppl 3:S3444.

5. IONA Study Group. Effect of nicorandil on coronary events in patients with stable angina: the Impact of Nicorandil in Angina (IONA) randomised trial. Lancet. 2002 Apr 13;359(9314):126975

6. Cribier B, Marquart-Elbaz C, Lipsker D, Alt M, Grosshans E. Chronic buccal ulceration induced by nicorandil. Br J Dermatol. 1998 Feb;138(2):372-3.

7. Vella M, Molloy RG. Nicorandil-associated anal ulceration. Lancet. 2002 Dec 14;360(9349):1979.

8. Katory M, Davies B, Kelty C, Arasaradnam R, Skinner P, Brown S, et al. Nicorandil and idiopathic anal ulceration. Dis Colon Rectum. 2005 Jul;48(7):1442-6.

9. Erzingatsian K. Re: Perforation of the terminal ileum: a possible complication of nicorandil therapy. Surg JR Coll Surg Edinb Irel. 2004 February 2, 56-57. Surgeon. 2004 Oct;2(5):2967; author reply 297.

10. Brown R, Lee A, Welfare M. Nicorandil-induced colonic ulceration. Heart. 2008 May;94(5):678

11. Ogden S, Mukasa Y, Lyon CC, Coulson IH. Nicorandilinduced peristomal ulcers: is nicorandil also associated with gastrointestinal fistula formation? Br J Dermatol. 2007 Mar;156(3):608-9.

12. Jennesseaux I, Carre-Gislard D, Bravard P. Nicorandilinduced cutaneous ulceration on a pacemaker implantation wound. Ann Dermatol Venereol. 2008 Feb;135(2):131-3.

13. Claeys A, Weber-Muller F, Trechot P, Cuny JF, Georges MY, Barbaud A, et al. Cutaneous, perivulvar and perianal ulcerations induced by nicorandil. Br J Dermatol. 2006 Aug;155(2):494-6.

14. Birnie A, Dearing N, Littlewood S, Carlin E. Nicorandilinduced ulceration of the penis. Clin Exp Dermatol. 2008 Mar;33(2):215-6.

15. Katory M, Davies B, Arasaradnam R, Skinner P, Brown S, Shorthouse AJ, et al. Nicorandil associated anal ulceration. Colorectal Dis. 2004 Nov;6(6):527.

16. Abdelrazeq AS, Owen C, Smith L, McAdam JG, Pearson $\mathrm{HJ}$, Leveson $\mathrm{SH}$, et al. Nicorandil-associated para-stomal ulceration: Case series. Eur J Gastroenterol Hepatol. 2006 Dec;18(12):1293-5.

17. Miura S, Kurose I, Fukumura D, Suematsu M, Sekizuka $\mathrm{E}$, Tashiro $\mathrm{H}$, et al. Ischemic bowel necrosis induced by endothelin-1: an experimental model in rats. Digestion. 1991;48(3):163-72

18. Healy CM, Smyth Y, Flint SR. Persistent nicorandil induced oral ulceration. Heart. 2004 Jul;90(7):e38.

19. Madinier I, Berry N, Chichmanian RM. Drug-induced oral ulcerations. Ann Med Interne (Paris). 2000 Jun;151(4):248-54.

20. Baker RP, Al-Kubati W, Atuf M, Phillips RK. Nicorandilinduced severe perianal ulceration. Tech Coloproctol. 2007 Dec;11(4):343-5.

21. Toquero L, Briggs CD, Bassuini MM, Rochester JR. Anal ulceration associated with Nicorandil: case series and review of the literature. Colorectal Dis. 2006 Oct;8(8):717-20.

22. Williams C, Tamuno P, Smith AJ, Walker SL, Lyon CC. Perianal ulceration and other cutaneous ulcerations complicating nicorandil therapy. J Am Acad Dermatol. 2007 May;56(5 Suppl):S116-7.

23. World Health organisation. World health report 1997: conquering suffering, enriching humanity. Switzerland: WHO; 1997. p. 39.

24. Pearson TA. Cardiovascular disease in developing countries: myths, realties and opportunities. Cardiovasc Drugs Ther. 1999 Apr;13(2):95-104.

25. Pais P. Preventing ischaemic heart disease in developing countries. Evid Based Cardiovasc Med. 2006 Jun;10(2):85-8. 